\title{
INTERIORIZAÇÃO DA EDUCAÇÃO SUPERIOR: DEMANDAS DE DEMOCRATIZAÇÃO E PARCERIA COM O PODER PÚBLICO MUNICIPAL
}

\author{
M. E. DE ANDRADE \\ Universidade do Estado do Rio Grande do Norte - UERN \\ edgleumadeandrade@yahoo.com.br
}

Artigo submetido em junho/2014 e aceito em abril/2015

DOI: $10.15628 /$ holos.2015.2192

\section{RESUMO}

Este artigo analisa a política de expansão da Universidade do Estado do Rio Grande do Norte (UERN) no tocante a criação dos Núcleos Avançados de Educação Superior (NAES), que ampliou a interiorização da educação superior em diversos municípios do Estado por meio de parceria com os poderes públicos municipais. O recorte da pesquisa é referente ao período de 2002 a 2010. Nosso estudo tem caráter descritivo, com abordagem qualitativa. A metodologia envolveu a revisão bibliográfica da literatura e pesquisa documental, através da análise de documentos oficiais referentes à legislação e dados institucionais. Os resultados apontaram que a expansão por meio dos NAES, ampliou o acesso ao ensino superior em diferentes municípios do Estado, mas ainda apresenta limitações nas condições de oferta do ensino superior. Essa política de expansão da UERN ainda precisa de ações que a qualifiquem no sentido da efetiva democratização, em contraponto às demandas imediatas e à tutela dos executivos municipais.

PALAVRAS-CHAVE: Educação superior, expansão, democratização.

\section{INTERIORIZATION OF HIGHER EDUCATION: DEMOCRATISATION DEMANDS AND PARTNERSHIP WITH THE PUBLIC MUNICIPAL}

\begin{abstract}
This article analyzes the political expansion of the University of Rio Grande do Norte (UERN) regarding the creation of the Advanced Centers for Higher Education (NAES), which increased the internalization of higher education in several municipalities in the state through a partnership with municipal government. The outline of the research is related to the period 2002-2010. Our study is descriptive, qualitative approach. The methodology involved a literature review and
\end{abstract}

documentary research, through analysis of official documents related to legislation and institutional data. Results showed that the expansion through NAES, expanded access to higher education in different districts of the State, but still has limitations in terms of provision of higher education. This expansion policy UERN still needs actions that qualify towards effective democratization, in contrast to the immediate demands and the protection of the municipal executive

KEYWORDS: Higher education, expansion, democratization. 


\section{INTRODUÇÃO}

A Universidade do Estado do Rio Grande do Norte (UERN), na última década alcançou ampliação na oferta de vagas, abertura de novos cursos, faculdades, incorporação da PósGraduação stricto sensu, aliada a ampliação de suas unidades em diversas regiões do Estado.

Dentre as ações da política de expansão da UERN merece destaque a criação dos Núcleos Avançados de Educação Superior (NAES), autorizado pelo Governo Estadual através Lei no 8.221, de 12 de agosto de 2002, que dispõe sobre autorização dos NAES, vinculado à Universidade do Estado do Rio Grande do Norte. Através dos NAES, a UERN passaria a ter unidades acadêmicas com oferta de cursos em vários municípios, por meio de parceria com prefeituras municipais, a ser firmada através de convênio, em que a Universidade se responsabilizaria pela parte pedagógica no que se refere a autorizar a oferta de cursos e disponibilizar seu quadro docente; e as prefeituras dispostas a sediar um Núcleo teriam por competência providenciar o prédio com a infraestrutura necessária ao funcionamento dos cursos.

Diante desse cenário, esse estudo teve como recorte o período de 2002 a 2010, e questionou-se a política de expansão da UERN por meio da criação dos NAES, no tocante às condições de democratização e qualidade da educação ofertada, em atendimento aos princípios do que caracteriza uma universidade. Com isso, elencam-se alguns questionamentos: Como se configura a política de expansão da UERN através dos Núcleos? Em que medida a expansão por meio dos NAES tem se caracterizado como um processo de democratização?

Trata-se de um estudo de caso, pautado em uma abordagem qualitativa. A importância desse tipo de investigação tem muito a ver com as questões que coloca e não apenas com as respostas que formula no sentido de que o aporte teórico contextualizado no estudo se constitui relevante no seu valor global que resulta tanto das suas características intrínsecas como da forma em que se contextualiza a estudos anteriores e expande os seus resultados (YIN, 2005).

A metodologia envolveu a revisão bibliográfica da literatura pertinente e a pesquisa documental, através da análise de documentos institucionais da UERN (resoluções, relatórios de gestão, plano de desenvolvimento institucional dentre outros) no sentido de analisar os desdobramentos de sua política de expansão. Os dados foram tratados com base no método descritivo analítico (TRIVIÑOS, 1987). Os aportes teóricos partiram dos conceitos de sustentabilidade da mudança (CLARK, 2004), aliado à lógica emancipatória (SANTOS, 2006).

Parte-se do pressuposto de que com a criação dos NAES ampliaram-se as oportunidades de acesso ao ensino superior por meio da oferta de cursos em diversos municípios do Estado. No entanto, as ofertas são questionáveis no que se refere às condições efetivas de democratização e qualidade do ensino ofertado.

\section{CARACTERIZAÇÃO DA UERN}

A UERN, com sede na cidade de Mossoró-RN, onde funciona seu Campus Central, foi criada pela Lei Municipal no 20, de 28 de setembro de 1968, a partir da junção de faculdades isoladas: Faculdade de Ciências Econômicas de Mossoró, Faculdade de Serviço Social, Faculdade de Filosofia, Ciências e Letras e a Escola Superior de Enfermagem. 
Na década de 1970, a instituição é ampliada com a criação dos Campi Avançados de Açu (1974), Pau dos Ferros (1976) e Patu (1980), resultado de articulações dos poderes políticos de Mossoró e dos demais municípios. Em 1987 ocorre a estadualização, assinada pelo então governador Radir Pereira, através da Lei n. 5.546/87. A UERN foi reconhecida pelo Conselho Federal de Educação através da Portaria Ministerial no 874, de 17 de junho de 1993, e do Decreto no 83.857, de 15 de agosto de 1993, após um período de quatro anos de acompanhamento, conforme expressa o Parecer n 184/89 do Conselho Federal de Educação (UERN, 2008a).

A partir de 2002, intensifica-se uma nova fase de expansão geográfica, com a criação de dois campi: o Campus Avançado de Natal e o Campus Avançado de Caicó. É também no ano de 2002 que é criado um novo tipo de unidade acadêmica: os Núcleos Avançados de Educação Superior, através da oferta de cursos isolados em diversos municípios do Estado. Com esse processo, no ano de 2006, a UERN adquire abrangência espacial presente em todas as regiões do Estado, formada por um Campus Central (Mossoró), 05 (cinco) Campi Avançados (Açu, Patu, Pau dos Ferros, Natal e Caicó) e por 11 (onze) Núcleos Avançados de Educação Superior que funcionam nos municípios de Caraúbas, Apodi, Areia Branca, Alexandria, Umarizal, São Miguel, Macau, Touros, João Câmara, Nova Cruz e Santa Cruz (UERN, 2008a).

\section{OS NAES NO CONTEXTO DA POLÍTICA EXPANSÃO DA UERN}

No contexto de inúmeras mudanças, e da expansão da Educação Superior, que se faz presente em âmbito internacional, nacional e local, a universidade, conforme afirma Fávero (1998), deve responder a esses "progressos" positivamente, não só se reformulando para o atendimento das novas necessidades, como também, e principalmente, fazendo a crítica dessas novas realidades.

Dito isso, emerge o questionamento sobre a configuração da política de expansão da UERN na perspectiva da sustentabilidade institucional, em dar respostas positivas, que potencialize melhorias em sua realidade. Essa realidade exige da universidade novas capacidades de respostas institucionais para a realização sustentável da sua expansão, sem deixar de cumprir a missão maior da universidade que é a produção e o uso do conhecimento como um bem público.

Nesse cenário de expansão e demandas de democratização do ensino superior, a UERN mobilizou ações para sua ampliação. E uma dessas ações é referente à criação dos NAES. No entanto, essa política de expansão não foi em sua totalidade previamente discutida nos colegiados e inviabilizou o projeto político pedagógico institucional em definir sua expansão. Em alguns casos, a criação de cursos e núcleos foi aprovada pela Assembleia Legislativa através de projetos de deputados, ferindo a autonomia pedagógica e administrativa da UERN. Cite-se como exemplo os Núcleos Avançados de Educação Superior que sofrem interferência políticopartidária, por meio de proposições de deputados ${ }^{1}$ junto à Assembleia Legislativa do RN, aprovando a criação de núcleos em alguns municípios, como é o caso do Núcleo de Santa Cruz, que passou a funcionar em 2006 com os cursos de Enfermagem e Ciências da Computação.

\footnotetext{
${ }^{1}$ Boletim Oficial 2249 - Requerimento do Deputado Ezequiel Ferreira/PTB, solicitando a implantação do Núcleo da UERN no município de Santa Cruz - Assembleia Legislativa do Estado do RN, Natal 13/12/2005.
} 
Os NAES foram instalados em cumprimento às ações da política de expansão da graduação da UERN, originalmente proposto na Agenda UERN 2001-2005 pelo então candidato a reeleição (2001) para reitor José Walter da Fonseca. É legítimo afirmar que os NAES representam ampliação do acesso ao ensino superior, no entanto, cabe considerar que as intencionalidades dessa expansão resultaram de barganhas políticas, que se intensifica a cada ano nos discursos dos políticos: de um lado os interesses políticos partidários em se beneficiar da expansão da UERN para manter a sustentação política dos detentores de mandato, fortalecer suas bases e conseguir votos para as próximas eleições, sob a justificativa do desenvolvimento regional; do outro lado, o então Reitor da UERN José Walter da Fonseca, que disputava a reeleição para o cargo de reitor em 2001, cuja promessa de campanha era a expansão dos cursos de graduação da UERN e ampliação da oferta de cursos por meio da criação dos núcleos em parceria com os municípios do Estado.

Nesse panorama, a UERN implantou, a partir de 2002, os NAES, em diversos municípios do Estado, por meio de convênios com algumas prefeituras. Os núcleos são unidades acadêmicas que ofertam cursos já existentes na instituição, de modo que estão vinculados pedagogicamente aos departamentos dos campi, seguindo as mesmas diretrizes curriculares expressas no Projeto Pedagógico do curso de origem. Os cursos ofertados pelos núcleos são temporários, pois têm caráter rotativo, sendo que cada curso deve ser ofertado por, no mínimo, em dois vestibulares consecutivos, e o corpo docente é constituído por professores lotados nos departamentos-sede e se deslocam para dar aulas nessas unidades. No total, são onze núcleos, sendo que os dois últimos foram implantados em 2006 nos municípios de Santa Cruz e Nova Cruz.

A Resolução no 002/2002 - CONSUNI regulamentou o Programa de Interiorização da UERN, por meio da implantação de Núcleos Avançados de Educação Superior. Conforme a resolução, os cursos ofertados nos núcleos têm caráter rotativo, de acordo com a demanda existente nas diversas regiões do Estado e, mais especificamente dos municípios. Ainda, segundo o documento, os argumentos em favor desse novo tipo de unidade acadêmica vão ao encontro das proposições do Parágrafo único do art. 26 do Estatuto da UERN "Os cursos ministrados nos Campi, prioritariamente, são destinados à formação de recursos humanos para a educação e de profissionais que venham a atender às necessidades emergentes" (RESOLUÇÃO no 09/97 CONSUNI).

Os cursos em funcionamento, e que já foram ofertados nos vestibulares para os núcleos desde 2002, distribuem-se entre bacharelados e licenciaturas. A maioria destes funciona no período noturno, conforme se observa na Tab. 1 a seguir:

Tabela 1 - Cursos ofertados nos NAES de 2002 a 2010

\begin{tabular}{c|c|c}
\hline Cursos & Turno & Núcleos/municípios \\
\hline Administração - B & $\mathrm{N}$ & Caraúbas, Macau \\
Ciência da Computação - B & MT & Santa Cruz \\
Gestão Ambiental - B & $\mathrm{N}$ & Areia Branca \\
Turismo - B & $\mathrm{N}$ & Areia Branca, Touros \\
Direito - B & $\mathrm{N}$ & Nova Cruz \\
Ciências Contábeis - B & $\mathrm{N}$ & Alexandria, João Câmara, Macau, São \\
Ciências Econômicas -B & & Miguel \\
Enfermagem - L/B & $\mathrm{N}$ & Umarizal \\
Educação Física - L & $\mathrm{MT}$ & Santa Cruz \\
\hline
\end{tabular}




\begin{tabular}{c|c|c}
\hline Física -L & N & São Miguel, Touros. \\
Geografia - L & N & Caraúbas \\
Ciências Biológicas - L & N & São Miguel, Touros \\
História - L & N & Alexandria, João Câmara. \\
Letras - L - Língua Espanhola & N & Apodi \\
Letras L - Língua Inglesa & N & Apodi, Macau, Umarizal \\
Letras - L - Língua Portuguesa & N & Apodi, Macau, Umarizal \\
Matemática -L & N & São Miguel, Touros, Apodi \\
Pedagogia - L & N & Alexandria, Caraúbas \\
Química - L & N & São Miguel, Touros \\
\hline
\end{tabular}

Fonte: PROPEG/UERN

Legenda: L - Licenciatura; B - Bacharelado; N - Noturno; MT - Manhã e Tarde.

De acordo com a Resolução no 002/2002 - CONSUNI, o funcionamento e manutenção dos Núcleos são assegurados por meio de convênio específico firmado entre a UERN e Prefeituras Municipais que os sediarão. Compete às prefeituras providenciar o prédio com as devidas condições estruturais para funcionamento dos cursos, ou seja, garantir as instalações físicas e equipamentos, inclusive de tecnologias educacionais, e assegurar o pessoal técnicoadministrativo (indicar e remunerar). À Universidade compete autorizar a oferta dos cursos, vez que os núcleos estão vinculados academicamente aos campi, além de disponibilizar o deslocamento do corpo docente dos diversos campi para ministrarem aulas nos núcleos; nomear um coordenador pedagógico dentro do quadro efetivo da instituição para cada curso ofertado; e, responsabilizar-se pela aquisição de livros para a biblioteca dos núcleos.

No tocante à estrutura administrativa dos Núcleos Avançados de Educação Superior, esta compete às prefeituras, conforme a Resolução no 05/2008 - CONSUNI, que é composta por: um coordenador administrativo, nomeado pela prefeitura municipal, que tenha nível superior completo e experiência na gestão pública - cuja função é administrar e coordenar as atividades técnico-administrativas do núcleo; um secretário de núcleo, com formação mínima em nível superior, e um auxiliar de biblioteca, com formação mínima em nível médio, indicados pela prefeitura municipal. Essas três funções citadas devem existir em todos os núcleos, sendo que outras funções administrativas existirão, somente, no caso de necessidade, de acordo com cada curso ofertado, a ser definidas em convênio firmado entre a UERN e as prefeituras. Já com relação à gestão pedagógica, esta é de competência da Universidade, que deverá dispor de um Coordenador Pedagógico para cada curso ofertado no núcleo, sendo este um professor efetivo, escolhido em plenária departamental do seu curso e nomeado pelo Reitor através de portaria.

Os campi responsáveis pelos devidos núcleos têm autonomia para definir critérios para encaminhar docentes do seu quadro para ministrarem aulas nos núcleos. Isso tem ocasionado uma sobrecarga e concentração de trabalho dos docentes efetivos da instituição no âmbito do ensino, em detrimento de outras atividades acadêmicas, já que as atividades (docente ou coordenador pedagógico de curso) desenvolvidas nos núcleos são externas ao regime de trabalho (20h, 40h ou Dedicação Exclusiva), ou seja, não são contabilizadas na distribuição da carga horária do docente. Desse modo, os núcleos representam uma atividade paralela dos docentes, e os que se dispõem a ensinar nessas unidades recebem em seu contracheque um incentivo financeiro de $40 \%$ sobre o seu salário base.

Embora o conteúdo da Resolução no 002/2002 - CONSUNI afirme, em seu art. 2ㅇ -“Fica a Reitoria autorizada a instalar, através de portaria, Núcleos Avançados de Educação Superior, em 
municípios cuja viabilidade pedagógica, administrativa e financeira assim o permitir", o que se observa é uma expansão realizada sem as condições necessárias ao seu funcionamento, com uma série de problemas no que se refere ao espaço físico e equipamentos, laboratórios, dificuldades de organização de vida acadêmica para o corpo discente e docente; ausência de autonomia dos núcleos, pois estes não contam com dotação orçamentária própria, ficando na dependência do executivo municipal para melhorias em sua infraestrutura.

A implantação e oferta de cursos nos Núcleos também demonstra a inexistência de um planejamento organizado no que concerne à expansão. A localização dos núcleos é um exemplo de ausência de planejamento, pois o fato de ter sido autorizada a criação dessas unidades em municípios limítrofes aos campi, coloca em questionamento a justificativa de existência de unidades tão próximas, quando se poderiam implantar cursos nos campi, com autonomia para definição orçamentária. Esse é o caso, por exemplo, de Mossoró e seu Núcleo de Areia Branca, Patu e seu Núcleo de Alexandria, que ficam a menos de $70 \mathrm{~km}$ dos campi.

A problemática no âmbito do planejamento refere-se também, à escolha de cursos ofertados e às condições de seu funcionamento. Essa é a situação dos Núcleos de São Miguel (a $36 \mathrm{~km}$ do Campus de Pau dos Ferros) e Touros (a $84 \mathrm{~km}$ do Campus de Natal) que, apesar de próximos de outros campi, são coordenados pelo Campus de Mossoró em função de os cursos ofertados nesses dois núcleos (Biologia, Física, Matemática, Química) só existirem no Campus Central, de modo que se tem a precarização do trabalho dos docentes que se deslocam de Mossoró e levam de três a quatro horas para chegar nessas unidades.

Outro fato, neste contexto, é a oferta dos cursos de Turismo e Gestão Ambiental, a partir de 2003, no Núcleo de Areia Branca - coordenados pelo Campus Central - Mossoró (onde não existiam os referidos cursos). O curso de Gestão Ambiental não existia no âmbito da UERN e o de Turismo tinha sido criado em Natal, em 2002. Essa situação ameaçou o reconhecimento dos referidos cursos nos Núcleos que, em 2007, iriam formar as suas primeiras turmas, já que, segundo a Resolução n.o 01/2001- CEE/RN do Conselho Estadual de Educação, uma das condições para curso ofertado fora de sede ser reconhecido é o mesmo já existir na instituição. Desta feita foram criados em 2007 os cursos de Gestão Ambiental e Turismo por meio de Resoluções institucionais no Campus Central em Mossoró, que passaram a ser ofertados a partir de 2008.

O panorama exposto demonstra ausência de critérios qualitativos na operacionalidade dessas unidades, de forma a comprometer a qualidade na formação. A Resolução no 002/2002 CONSUNI, não esclarece como se dará os critérios de escolha dos cursos a serem ofertados, apenas afirma, no seu art. 3 que a oferta será conforme a demanda existente. No entanto, não foi localizado nenhum documento com estudo sobre essa demanda.

A complexidade da UERN coloca-se no fato de ela se constituir como uma universidade multicampi que, segundo Fialho (2005), configura-se pela desconcentração organizacional e dispersão física, e que tende ao mesmo risco de desintegração da vida universitária, tal qual se observa em relação à implantação do modelo universitário no Brasil. Diante disso, a universidade reconhece a complexidade de lidar com as mudanças em um cenário de heterogeneidade institucional:

O caráter multicampi da UERN, recentemente acrescido dos Núcleos Avançados de Educação Superior, confere à instituição maior complexidade. A dispersão 
espacial coloca o desafio de encontrarem-se ferramentas e práticas administrativas que minimizem seus efeitos negativos e façam-na funcionar como positividade, pela diversidade de realidades humanas, sociais e institucionais que agrega. A distância geográfica coloca problemas de comunicação, de homogeneidade de procedimentos e eleva gastos financeiros como decorrência mesma da natureza da estrutura. (UERN, 2008a).

Conforme se observa acima, a UERN reconhece os desafios dessa nova forma de organização, e os efeitos negativos decorrentes dessa dispersão espacial, no qual se incluem os NAES. Porém, nos documentos analisados não está previsto nenhum mecanismo para incorporar os cursos dos Núcleos aos campi existentes, extingui-los ou rever os convênios para melhoria de funcionamento dos mesmos.

Essa realidade de parcerias com o poder público municipal ocorre em diversas universidades públicas, incluindo-se federais e estaduais, tais como ocorreu com a Universidade Federal de Goiás, segundo estudo de Dourado (2001). E, reforça como se percebe em nosso estudo uma situação de tutela dos executivos municipais, conforme aponta Dourado (2001), de que com a criação de estabelecimentos isolados se proclama o discurso da modernização e desenvolvimento regional, mas tem como norte uma política de defesa de um processo de gestão que racionalize e otimize os recursos existentes. Uma vez que, conforme os documentos que analisamos há ausência de previsão de dotação orçamentária por parte da UERN para infraestrutura dessas unidades, bem como de admissão de novos docentes por meio de concurso público para atender essa nova demanda.

Esse quadro nos remete a pensar a perspectiva de sustentabilidade institucional Clark (2004), de uma universidade, que reside na adoção e manutenção de políticas e práticas acadêmicas capazes de conduzir para a mudança contínua do instituído, no sentido de avançar e assumir os riscos existentes, cujas bases de realização subtendem desde uma gestão universitária fortalecida e comprometida com melhorias, financiamento diversificado, uma cultura de mudança até práticas e/ou políticas de estímulo acadêmico. Ainda conforme esse autor, as demandas e desafios em si não vão determinar o destino das universidades; mas, em vez disso, como as universidades respondem as muitas forças que atuam sobre elas, se torna o cerne da questão.

\section{DEMANDAS DE DEMOCRATIZAÇÃO E CONDIÇÕES DE OFERTA DE ENSINO NOS NAES}

Falar em democratização implica assegurar o direito a todos de educação pública de qualidade, com oportunidades iguais de formação. Nesse sentido, entende-se que a perspectiva multidimensional da qualidade, ao considerar a educação como bem público, respeitando o contexto e as especificidades locais, distancia-se do que ocorre com os Núcleos, pois nestes há diferenciação nas oportunidades de formação dentro de uma mesma instituição (DIAS SOBRINHO, 2008, 2010; MOROSINI, 2009; UNESCO, 1998). É insuficiente apenas afirmar que esses cursos vão possibilitar o desenvolvimento local dos municípios atendidos, sem pensar em quais direções estes se consolidariam em longo prazo, uma vez que a perspectiva multidimensional da qualidade implica em que as instituições devam estar respaldadas localmente, mas ao mesmo tempo comprometidas com a construção do conhecimento de forma 
mais ampla frente às inúmeras transformações no mundo e das incertezas da sociedade global. Pois tal como argumenta Santos (2006), o grande desafio da universidade é a sua responsabilidade pelo futuro.

A oferta de cursos nos Núcleos passa a ser regulamentada através da Resolução no 067/2005 - CONSEPE, de 21 de dezembro de 2005, que disciplina a oferta, a suspensão de vagas iniciais e a avaliação dos cursos de graduação nos Núcleos Avançados de Educação Superior. Conforme o documento, a oferta de vagas iniciais (Processo Seletivo Vocacionado - PSV vestibular constituído de provas por grupos de disciplinas afins aos cursos ofertados) dos cursos de graduação nos Núcleos far-se-á em observância a algumas diretrizes:

a) comprovação da existência de demanda regional por formação de profissionais através de pesquisa técnica conduzida pela UERN (constituída por comissão com membros das próreitorias e representantes da educação nos municípios sede dos núcleos) no que concerne à viabilidade pedagógica, administrativa e financeira de oferta de cursos;

b) aprovação pelo CONSEPE da proposta de oferta de vagas enviada pelo Campus responsável pelo(s) curso(s);

c) convênio firmado com as prefeituras que assegure pessoal técnico, instalações e equipamentos para funcionamento do(s) curso(s);

d) oferta de vagas iniciais para no máximo de 02 (dois) cursos por núcleo;

e) oferta de vagas inicias por no mínimo 02(dois) vestibulares consecutivos;

f) ofertas de vagas para novo curso, somente depois de decorrido 02 (dois) anos de suspensão de vaga inicial em curso já existente,

g) processo de avaliação dos Cursos de Graduação dos Núcleos, conduzido por uma comissão nomeada pelo Reitor, coordenado pelo assessor de avaliação institucional, juntamente com membros das pró-reitorias e representante discente.

Os desdobramentos concretos de implantação dos Núcleos apontam a inexistência de um programa de avaliação sistemática do funcionamento dos cursos, ou mesmo de redirecionamento, no sentido de incorporar a estrutura física dos cursos aos campi que lhes são responsáveis, fato esse que observado pela ausência de relatórios técnicos de avaliação específica sobre os núcleos, quando solicitados ao setor de assessoria na Pró-Reitoria de Ensino de Graduação.

Já com relação à oferta de vagas iniciais (no vestibular - PSV), observa-se conforme a Tab. 2, que tem sido cumprida, nos últimos anos a oferta de no máximo 02 (dois) cursos por núcleo:

Tabela 2 - Número de cursos ofertados no PSV nos núcleos 2002-2010

\begin{tabular}{c|c|c|c|c|c|c|c|c|c}
\hline Núcleos & $\mathbf{2 0 0 2}$ & $\mathbf{2 0 0 3}$ & $\mathbf{2 0 0 4}$ & $\mathbf{2 0 0 5}$ & $\mathbf{2 0 0 6}$ & $\mathbf{2 0 0 7}$ & $\mathbf{2 0 0 8}$ & $\mathbf{2 0 0 9}$ & $\mathbf{2 0 1 0}$ \\
\hline Alexandria & 1 & 2 & 2 & 2 & 2 & 1 & 1 & 1 & 1 \\
Areia Branca & 1 & 2 & 2 & 2 & 2 & 1 & 0 & 0 & 0 \\
Caraúbas & 1 & 2 & 2 & 2 & 2 & 1 & 1 & 1 & 1 \\
João Câmara & 1 & 2 & 2 & 1 & 1 & 1 & 1 & 1 & 1 \\
Macau & 1 & 2 & 2 & 1 & 1 & 1 & 1 & 2 & 2 \\
Nova Cruz & 0 & 0 & 0 & 0 & 2 & 2 & 2 & 2 & 2 \\
Santa Cruz & 0 & 0 & 0 & 0 & 2 & 1 & 1 & 1 & 1 \\
São Miguel & 1 & 4 & 4 & 0 & 0 & 0 & 0 & 1 & 1 \\
Touros & 0 & 4 & 4 & 0 & 0 & 0 & 0 & 0 & 0 \\
Umarizal & 0 & 2 & 2 & $3^{*}$ & $3 *$ & 0 & 0 & 2 & 2 \\
Total & 7 & 22 & 23 & 13 & 15 & 9 & 8 & 13 & 13 \\
\hline
\end{tabular}

Fonte: COMPERVE/UERN *A oferta de 03 cursos no referido núcleo pode ser justificada pelo fato 
de o vestibular de 2005 e 2006 ter sido anterior à Resolução no 067/2005 CONSEPE.

A partir de 2005, inicia-se o processo de rotatividade dos cursos, com a continuidade de oferta de vagas no vestibular de cursos já existentes e suspensão de outros, conforme regulamenta a Resolução no 002/2002 - CONSUNI, sobre o caráter rotativo dos cursos ofertados nos núcleos. Com essa ação, juntando-se os cursos já em funcionamento (com vagas suspensas no vestibular) e os que terão vagas iniciais, permanece em funcionamento nos núcleos uma média de 30 cursos por ano, conforme se observa na Tab. 3.

Tabela 3 - Número de oferta e suspensão de vagas nos cursos dos núcleos

\begin{tabular}{|c|c|c|c|c|c|c|c|c|}
\hline \multirow[t]{2}{*}{ Núcleos } & \multicolumn{2}{|c|}{2005} & \multicolumn{2}{|c|}{2006} & \multicolumn{2}{|c|}{2007} & \multicolumn{2}{|c|}{2008} \\
\hline & $\begin{array}{c}\text { Oferta } \\
13\end{array}$ & $\begin{array}{c}\text { Susp. } \\
11\end{array}$ & $\begin{array}{c}\text { Oferta } \\
15\end{array}$ & $\begin{array}{c}\text { Susp. } \\
13\end{array}$ & $\begin{array}{c}\text { Oferta } \\
09\end{array}$ & $\begin{array}{c}\text { Susp. } \\
21\end{array}$ & $\begin{array}{c}\text { Oferta } \\
08\end{array}$ & $\begin{array}{c}\text { Susp. } \\
23\end{array}$ \\
\hline Total dos cursos & \multicolumn{2}{|c|}{24} & \multicolumn{2}{|c|}{28} & \multicolumn{2}{|c|}{30} & \multicolumn{2}{|c|}{31} \\
\hline
\end{tabular}

Fonte: COMPERVE/UERN.

Legenda: Susp. : suspenso

No âmbito da qualidade do ensino ofertado, o ENADE, que é um dos indicadores na avaliação dos cursos de graduação, demonstra as fragilidades dos cursos de graduação dos Núcleos. No período de 2004 a 2009, dos 27 cursos dos núcleos que foram avaliados pelo ENADE, vinte (20) ficaram Sem Conceito (SC) em função destes cursos só terem ingressantes ou só concluintes nos anos em que foram avaliados pelo ENADE, não reunindo, assim, elementos para estabelecer o conceito de curso. Isso se deve ao fato de que, como nos núcleos os cursos são rotativos, dificilmente se tem ingressantes e concluintes no mesmo ano. Os demais cursos avaliados tiveram os seguintes resultados: três cursos foram avaliados com conceito 3 (Letras em Umarizal, Educação Física em João Câmara e Pedagogia em Caraúbas); quatro cursos tiveram avaliação insatisfatória (os cursos de História e de Ciências Contábeis em Alexandria, Ciências Econômicas em Umarizal e Turismo em Areia Branca) com Conceito Preliminar de Curso 2. Ressalte-se que os cursos avaliados como insatisfatórios não foram mais ofertados em suas respectivas unidades nos Núcleos, podendo-se inferir que seria uma decisão mais simples para sanar o problema, já que os cursos são rotativos, e não obrigaria a instituição a repensar melhorias para as deficiências apontadas pela avaliação. A descontinuidade e temporalidade dos cursos, por sua vez, demonstra a dificuldade de se pensar em melhorias a médio e longo prazo para os cursos e à formação dos alunos dos Núcleos.

Diante desse quadro, a forma como se caracterizam os núcleos coloca em questionamento a participação destes na ampliação e democratização do acesso ao ensino superior e a sua efetiva qualidade, pois estes apresentam vários desafios: a) a descaracterização de um espaço de fato acadêmico e universitário, em que se vivencie a articulação entre ensino, pesquisa e extensão. Os núcleos funcionam em prédios (escolas da Educação Básica e/ou adaptadas para o núcleo) disponibilizados pelas prefeituras municipais. O que se tem nos núcleos é um ambiente exclusivamente de ensino, em que o contato entre corpo docente e discente ocorre exclusivamente nos dias de aulas (ampliou-se o acesso, mas com oportunidades diferenciadas da formação existentes nos campi); b) a gestão administrativa fica sob a tutela das prefeituras locais, o que compromete a autonomia da Universidade no tocante à manutenção e funcionamento dos núcleos; c) a fragmentação da gestão pedagógica, que é de responsabilidade da UERN, é limitada já que os coordenadores pedagógicos dos cursos que são dos campi realizam 
apenas visitas semanais; d) o caráter rotativo dos cursos, sem oferta permanente, inviabiliza ações de melhorias a médio e longo prazo. Além desses desafios, a Universidade disponibiliza sua frota de veículos para o deslocamento de docentes aos núcleos (são 17 rotas diárias), ocupando veículos que poderiam ser utilizados para aulas de campo e eventos.

No âmbito das atividades acadêmicas (monitoria, pesquisa e extensão), estas são desenvolvidas apenas nos campi da UERN, porém, ausente nos Núcleos Avançados de Educação Superior. Conforme os dados do Censo da instituição, docentes que atuam nos Núcleos desenvolvem atividades dessa natureza em seus campi de origem, sem nenhum registro de discentes dos Núcleos desenvolvendo atividades de monitoria, pesquisa e extensão, seja na modalidade com bolsa ou voluntário. Porém, essas atividades estão previstas nos dispositivos institucionais que regulamentam os Núcleos, como, por exemplo, quando se define como competência do coordenador pedagógico (UERN) de cursos dos núcleos, "coordenar o trabalho dos docentes do curso, visando à integração e à eficiência do ensino, pesquisa e extensão", e também compete ao coordenador administrativo dos núcleos (prefeituras) "sugerir providências cabíveis para maior eficiência do ensino, pesquisa e extensão" (RESOLUÇÃO no 5/2008 CONSUNI). No entanto, as condições de funcionamento dessas unidades acadêmicas inviabilizam atividades dessa natureza: a presença de docentes e discentes nos núcleos só ocorre para ministrar e assistir aulas, respectivamente, salvo raras exceções em que o discente se faz presente para consultar livros na biblioteca ou utilizar o laboratório de informática dessas unidades; a presença do coordenador pedagógico nos núcleos é semanal, o que dificulta um acompanhamento contínuo; o coordenador administrativo, que funciona como um "diretor" do núcleo, é pouco provável que venha "sugerir maior eficiência", em atividades que sequer existem ou tenham condições reais de acontecer, e que sua viabilidade poderia implicar em custos para a prefeitura, caso fossem necessários equipamentos ou estrutura física, e também se acrescente que, pelo fato deste não compor o quadro docente da universidade, desconhece as necessidades inerentes à vida acadêmica.

Desse modo, as oportunidades educacionais dentro da UERN são diferenciadas, a realidade dos campi difere dos núcleos o que se distancia de uma perspectiva de democratização enquanto ampliação das oportunidades, qualidade da educação ofertada e autonomia em definir os rumos institucionais. A efetiva ampliação da educação superior só se justifica com a garantia do sentido público do direito à educação, respeitando o contexto e as especificidades locais e garantindo igualdade de oportunidades de acesso e formação. Tal como afirma Santos (1995; 2004), essa crise do sentido público passa pela crescente descaracterização da universidade, que ocasiona o que ele chama de crise de hegemonia, na medida em que a universidade tem dificuldades de definir o seu papel. Portanto, esse quadro revela a dificuldade de a UERN definir suas finalidades em relação às exigências do conhecimento e da sociedade, levando em conta a heterogeneidade e especificidade de sua realidade, bem como o compromisso institucional com a democratização do acesso, permanência e qualidade.

Essa situação encontra sérias limitações do ponto de vista da autonomia institucional que, no caso dos núcleos, não é assumida pela comunidade acadêmica. A ausência da autonomia administrativa e financeira é legitimada pelo convênio firmado com as prefeituras, e a autonomia didático-científica é superficial ou, praticamente, inexistente, já que a UERN não consegue nem ao menos cumprir com o que regulamenta seu Estatuto no artigo 2ำ de 1997: "estabelecer sua política de ensino, pesquisa e extensão; criar, organizar, modificar, suspender e extinguir 
Faculdades, Departamentos, Cursos e disciplinas, de acordo com a realidade social". Isso é problemático no contexto operacional das ações, uma vez que, conforme argumenta Durham (2005), a liberdade acadêmica ou autonomia didático-científico constitui-se alicerce para a autonomia administrativa e de gestão financeira, as quais são instrumentais para a liberdade acadêmica.

Entende-se que a autonomia é relacional, resultado das contradições dialéticas no contexto no qual se insere, e sua redução ou ampliação tem relação direta com a ação política dos sujeitos envolvidos na universidade (CUNHA, 2006; DURHAM, 2003; FÁVERO, 2004; RANIERI, 1994). Em função disso argumenta-se sobre os espaços, lacunas, em que os sujeitos atuantes na UERN estão lutando, empreendendo ações para fazer cumprir o que é de sua competência, no sentido de definir e redirecionar os rumos da expansão, evitando influências às oscilações político-partidárias. No espaço empírico desta pesquisa, nem mesmo a autonomia administrativa e didático-cientifica tem sido uma realidade na UERN. Cite-se, como exemplo evidente nesse sentido, a existência dos Núcleos Avançados de Educação Superior - situação limitante e de precariedade do ensino superior, em que a universidade fica sob a tutela do executivo municipal. Conforme aponta Cury (1991), a autonomia implica autogoverno, em que a universidade opta por mecanismos próprios de autodireção, e que seja capaz de reconhecer os seus limites.

Esse panorama leva a refletir sob o prisma da expansão e, consequente, ampliação das oportunidades de acesso ao ensino superior. No tocante à qualidade, é clara e evidente dentro dos limites institucionais a ausência de um planejamento estratégico, pois a UERN aceitou expandir no "improviso" e, diante de situações precárias, torna-se cada vez mais vulnerável a influências, às oscilações externas, já que a criação e continuidade dos núcleos tem se caracterizado como uma decisão de interferência político-partidária, por meio da tutela das prefeituras municipais, a qual a Universidade vem se acomodando de forma passiva. Inexistem documentos institucionais que evidenciem um diagnóstico da necessidade, pertinência e relevância social da criação de cursos nos Núcleos. O conteúdo mais próximo com relação a isso se encontra nas resoluções pertinentes aos núcleos, ao utilizar a justificativa de atendimento a demandas emergentes e propiciar o desenvolvimento local. Entretanto, nem sempre a existência de uma instituição de ensino superior em determinada localidade é garantia de desenvolvimento para o Estado ou município, isso porque para tal é insuficiente a existência de qualquer instituição ou curso, é preciso se definir a relação deste com a realidade local, pensar uma política de longo prazo e não, unicamente, a questão "demanda emergente" - que atende ao imediato, ao improviso, e acaba por se tornar ação permanente e um comportamento padrão.

O quadro que se apresenta nos núcleos é incompatível com a perspectiva de universidade enquanto produtora de conhecimento e alicerçada sobre o tripé ensino, pesquisa e extensão. 0 que se processa com a expansão por meio dessas unidades é a inexistência de autonomia institucional por parte da Universidade no seu direcionamento e de dotação orçamentária que possa garantir melhorias infra estruturais e de manutenção das mesmas, caracterizando a precarização da formação e do quadro docente, descaracterizando por completo a perspectiva de universidade enquanto investimento de longo prazo, já que o atendimento visa suprir "necessidades emergentes" ou demandas imediatas solicitadas pelos municípios. Com isso podese inferir que esse tipo de ampliação de vagas se utiliza da eficiência, cujo objetivo único tem sido atingir a meta de ampliar a interiorização da UERN, sem se preocupar com bons resultados e em superar suas limitações, ou resolver os problemas que lhes são inerentes. 
Esse quadro aproxima-se a perspectiva de um ensino superior instrumental, visto como pronta aplicação ao desenvolvimento e indutor da economia, tal como preceitua o Banco Mundial (1995), em que, por conseguinte, a qualidade é identificada com medidas de controle da eficiência, orientada por mecanismos de avaliação do desempenho acadêmico. No entanto, no caso da UERN, a situação torna-se mais problemática, pois o ensino tem uma característica instrumental, mas o comportamento de "eficiência" em se fazer presente em vários municípios, através da ampliação da oferta de oportunidades educacionais, encerra-se por si mesmo, deixando de ser uma mensuração de resultados, sem controle do desempenho acadêmico, e passou a funcionar como um comportamento padrão, permanecendo na "zona de conforto" com a continuidade dessas unidades sem novos redirecionamentos.

É preciso reconhecer que ampliar vagas e ofertar cursos é necessário, mas insuficiente para a democratização do acesso, aliando-se a isso as condições acadêmicas para uma formação com qualidade, tendo em conta o tipo de formação que será desenvolvida para que se possa, de fato, favorecer as competências profissionais compatíveis com a demanda da sociedade. Dessa forma, de acordo com Dias Sobrinho (2010, p. 1239), "não basta qualquer saber, não é indiferente qualquer curso e qualquer diploma". O grande questionamento é sobre o tipo de democratização do acesso que se processa por meio dessas unidades acadêmicas onde se percebe a precarização do ensino superior, em que inexiste vida acadêmica, sem atividades de monitoria, extensão, pesquisas ou eventos acadêmicos de forma contínua. Tanto alunos quanto professores só vivenciam as aulas, o que caracteriza essas unidades como uma espécie de "escolão" de ensino superior.

\section{CONSIDERAÇÕES FINAIS}

O contexto institucional vivenciado pelos NAES que tem oferta flutuante de cursos, ainda que, reconhecidamente ampliou o acesso ao ensino superior em diferentes municípios do Estado, apresenta sérias limitações nas condições de oferta do ensino superior. É questionável o tipo de democratização e mesmo de qualidade existente por meio dessas unidades acadêmicas, onde é visível uma formação diferenciada dentro de uma mesma instituição, em que as atividades se concentram apenas em sala de aula, funcionando como uma espécie de "escolão" do ensino superior.

A expansão da UERN por meio dos NAES coloca em pauta o resgate do conceito de Universidade, respeitando os princípios definidos em lei para que se possa compreender as prioridades de investimentos e as concepções discursivas e operacionais sobre a Educação Superior. A perspectiva de articulação ensino, pesquisa e extensão é algo dispendioso e mesmo em instituições de excelência, limitações e riscos se fazem presentes. No entanto, não se justifica permanecer com essas unidades apenas como instrumento de ampliação do acesso sem proporcionar um ambiente de fato acadêmico.

O panorama dos Núcleos é uma situação contraditória da Universidade, que prefere continuar na "zona de conforto" em permanecer com os NAES, mesmo com as precárias condições existentes, quando se poderiam impulsionar mecanismos para absorver os cursos dessas unidades nos campi mais próximos. 
Nas condições em que se processa o funcionamento dos Núcleos e dos encaminhamentos da UERN em continuar com esse tipo de oferta, sem visualizar mudanças proativas em prol de melhoria da qualidade da Educação Superior, contrapõe-se a perspectiva de sustentabilidade da mudança voltada para ações que se coadunem com a qualidade de uma universidade capaz de cumprir e refletir sua função social. Nesse contexto, torna-se pertinente considerar os argumentos de Clark (2004) ao apontar que as alternativas de transformação das universidades seria iniciar a mudança enfrentando o medo do fracasso ou potencializar condições de sustentar mudanças bem-sucedidas.

Na UERN, o que se observa de forma enfática com relação aos núcleos é que a sua política de expansão não tem sido acompanhada de ações que a qualifiquem no sentido da sustentabilidade institucional, de modo que possa potencializar mudanças que reflitam a sua função social de delinear a construção de cenários futuros a médio e longo prazo, em contraponto às demandas urgentes e imediatas de apenas "certificar" a formação. A universidade tem colaborado para um ambiente instável ao atuar no curto prazo, renovando continuamente os convênios com as prefeituras para prosseguir com os cursos nos núcleos no sistema de rotatividade, sem que aja uma política efetiva de discussão dos mesmos e sua relação com o processo formativo no âmbito de uma universidade, no sentido de realmente democratizar o acesso com perspectivas reais de qualidade e sem a tutela dos executivos municipais.

Embora as universidades em geral tenham dificuldades em dar respostas de enfrentamento às pressões externas e internas, em razão de inúmeros fatores, e dentre eles o financiamento, urge questionar em que espaços e condições existem lacunas possíveis para viabilizar uma política de expansão qualificada, mantendo a legitimidade da função social da universidade. Nessa direção, Santos (1995) alerta sobre o risco de ações dispersas ou imediatistas por parte da universidade ao incorporar, de forma acrítica, as lógicas sociais e institucionais, pois ações, orientadas em curto prazo, tornarão a instituição cada vez mais instável. Ao passo que, mostra-se necessário o questionamento permanente da universidade no tocante as suas respostas de enfrentamento, rumo a uma lógica emancipatória, que se oriente por ações de longa duração.

\section{REFERÊNCIAS BIBLIOGRÁFICAS}

1. BANCO MUNDIAL. La Enseñanza Superior: las lecciones derivadas de la experiencia (EI Desarrollo en la práctica). Washington, D.C.: BIRD/Banco Mundial, 1995.

2. CLARK, B.R. Sustaining Change in Universities. Continuities in Case Studies and Concepts. Londres: Society for Research into Higher Education; Maidenhead: Open University Press, 2004.

3. CUNHA, L. A. Autonomia universitária: teoria e prática. In: Universidade investigación científica. VESSURI, H.(Org.). Buenos Aires: CLACSO, 2006.

4. CURY, C. R. J. A questão da autonomia universitária. Universidade e Sociedade. Brasília, DF, v. 1, n. 2, p. 25-29, nov. 1991.

5. DIAS SOBRINHO, J. Calidad, pertinencia y relevancia: relación conel resto del sistema y la sociedad; responsabilidad social de la educación superior. In: GAZZOLA, A.L.; PIRES, S. (Ed.). 
Hacia una política regional de aseguramiento de la calidad en educación superior para América Latina y el Caribe. Caracas: UNESCO-IESALC, 2008.

6.

Democratização, qualidade e crise da educação superior: faces da exclusão e limites da inclusão Educação \& Sociedade, Campinas, SP, v. 31, n.113, p.1223-1245, out./dez. 2010.

7. DOURADO, L. F. A Interiorização do Ensino Superior e a Privatização do Público. 1a. ed. Goiânia: Editora da UFG, 2001. v. 1.

8. DURHAM, E. R. A Autonomia Universitária: Extensão e Limites. São Paulo: NUPES/USP, 2005. (Série documentos de trabalho), 47p.

9. Autonomia, Controle e Avaliação. In Morhy, L. (Org.). Universidade em Questão. Brasília: UNB, 2003.

10. FÁVERO, M. L. A. Autonomia e poder na universidade: impasses e desafios. Perspectiva, Florianópolis, v. 22, n. 01, p. 197-226, jan./jun. 2004.

11. FÁVERO, M. L. A.. Universidade, pesquisa e iniciação científica: anotações para um debate. Cadernos de Sociologia, Porto Alegre, v. 8, p. 89-100, s/d, 1998.

12. FIALHO, N. H. Universidade multicampi. Brasília: Autores Associados: Plano Editora, 2005.

13. MOROSINI, M. C. Qualidade na educação superior: tendências do século. Est. Aval. Educ., São Paulo, v. 20, n. 43, p. 165- 186, maio/ago. 2009.

14. RANIERI, N. B. S. Autonomia universitária: as universidades públicas e a Constituição Federal de 1988. São Paulo: EDUSP, 1994.

15. RIO GRANDE DO NORTE. Conselho Estadual de Educação. Resolução no 01/2001, de 19 de dezembro de 2001. Regulamenta, para o sistema Estadual de Ensino, o reconhecimento e a renovação de reconhecimento de curso ou instituição de ensino superior credenciada. Natal: CEE, 2001.

16. Gabinete Civil. Lei no 8.221, de 12 de agosto de 2002. Dispõe sobre autorização para criação de Núcleos Avançados de Ensino Universitário, vinculado à Universidade do Estado do Rio Grande do Norte, e dá outras providências (UERN). Disponível em http://www.gabinetecivil.rn.gov.br/acess/lei_ordinaria_lista.asp?ano=2002. Acesso em 15 mar 2009.

17. SANTOS, B. S. Pela mão de Alice: o social e o político na pós-modernidade. São Paulo: Cortez, 1995.

18.

A universidade no século XXI: para uma reforma democrática e emancipatória da universidade. São Paulo: Cortez, 2004.

19.

A Crítica da razão indolente: contra o desperdício da experiência. São Paulo: Cortez, 2006.

20. TRIVIÑOS, A. N. S. Introdução à pesquisa em ciências sociais: a pesquisa qualitativa em educação. São Paulo: Atlas, 1987.

21. UNIVERSIDADE DO ESTADO DO RIO GRANDE DO NORTE. Conselho de Ensino, Pesquisa e Extensão. Resolução no 067/2005, de 21 de dezembro de 2005. Disciplina a oferta, a suspensão de vagas iniciais e a avaliação dos cursos de graduação nos Núcleos Avançados de Educação Superior. Mossoró, RN: UERN/CONSEPE, 2005. 
22. Conselho Universitário. Resolução no 07/1997, de 09 de dezembro de 1997. Aprova o Estatuto da Universidade do Estado do Rio Grande do Norte. Mossoró, RN: UERN/CONSUNI, 1997.

23. . Conselho Universitário. Resolução no 02/2002, de 13 de junho de 2002. Disciplina o Programa de Interiorização da UERN, por meio da implantação de Núcleos Avançados de Educação Superior. Mossoró, RN: UERN/CONSUNI, 2002.

24. . Conselho Universitário. Resolução no 05/2008, de 22 de agosto de 2008. Define competências dos Coordenadores Pedagógicos e Administrativos dos Núcleos Avançados de Educação Superior. Mossoró, RN: UERN/CONSUNI, 2008b.

25. . Plano de Desenvolvimento Institucional - (2008-2011). Mossoró, RN, 2008a.

26. . Reitoria. Relatórios de Gestão: (1997-2001); (2002-2005) Mossoró, RN, 2006.

27. UNESCO. Declaração Mundial sobre a Educação Superior XXI: visão e ação. Paris: UNESCO, 1998.

28. YIN, R. K. Estudo de caso: planejamento e métodos. Tradução Daniel Grassi, Porto Alegre: Bookman, 2005. 